\title{
O profissional da educação na Constituição Brasileira
}

Gilmar Soares Ferreira*

\begin{abstract}
RESUMO: O artigo mostra como as lacunas da legislação brasileira e as sucessivas gestões educacionais promovem de forma contínua a quebra de ações e o contingenciamento de recursos, e terminam por impedir o caminho rumo à qualidade social de nossa educação, que começa, principalmente, com investimento em pessoal e em sua profissionalização.

\section{Palavras-chave: Legislação educacional. Valorização profis- sional. Gestão da educação. Políticas para educação.}

\section{Introdução}

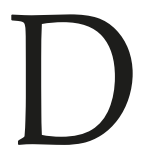

esde a conformação da Confederação dos Professores Brasileiros (CPB) à Confederação Nacional dos/as Trabalhadores/as (CNTE) da educação básica no Brasil, a luta pela profissionalização dos educadores brasileiros, incluindo professores/as e funcionários/as de escola, tem sido intensa.

Vivemos num país de intensas contradições econômicas, políticas e sociais. Mas, a mais significativa talvez seja a de uma elite que atua de forma corporativa para negar, constantemente, o direito à educação pública, gratuita e de qualidade socialmente referenciada à maioria da população.

\footnotetext{
Licenciado em Filosofia, especializado em Psicopedagogia. Professor efetivo da rede estadual de ensino do Estado de Mato Grosso (MT). Presidente, em terceiro mandato, da subsede de Várzea Grande do Sindicato dos Trabalhadores no Ensino Público de Mato Grosso (Sintep/MT). Secretário de formação Sindical da CNTE (licenciado) e de Comunicação do Sintep/MT (licenciado). Compõe o Conselho Técnico Científico de Educação Básica (CTC-EB) da Coordenação de Aperfeiçoamento de Pessoal de Nível Superior (Capes). Várzea Grande/MT - Brasil. E-mail: <gilmarsoares.ferreira@gmail.com>.
} 
Negar o direito à educação pública tem-se constituído o viés da dominação ideológica, no sentido negativo da acepção da palavra (GUARESCHI, 2000), principalmente pelo impedimento de assegurar de forma plena a profissionalização dos educadores no Brasil.

Somos um país que ainda carece de professores leigos em localidades de difícil acesso ou nas periferias do País. O percentual de professores que ainda carecem de formação de nível superior é significativo. Chama a atenção o número de professores que atuam fora de sua habilitação. Um dado de maior dramaticidade se mostra quando conhecemos os percentuais e profissionais contratados de forma precária nos mais de cinco mil sistemas de educação das três esferas de poder: municipal, estadual e federal.

Quanto aos/as funcionários/as de escola, a situação é mais alarmante. Do contingente de trabalhadores/as nas funções técnicas e administrativas nas unidades escolares, falta formação profissional, jornada digna, piso salarial, carreira e um real esforço de todos os segmentos para promover uma cultura de inclusão do profissional nos processos e relações de educação, de ensino e de aprendizagem.

Um dos entraves para avançar na profissionalização dos educadores no Brasil é, justamente, a legislação. Este breve artigo quer aproximar o leitor das lacunas da legislação brasileira, que, se do ponto de vista legislacional é um grande entrave para a profissionalização no Brasil, do ponto de vista das sucessivas gestões educacionais, que promovem de forma contínua a quebra de ações e o contingenciamento de recursos, terminam por impedir o caminho rumo à qualidade social da educação, que começa, principalmente, com investimento em pessoal e na sua profissionalização.

\section{O que é ser um profissional da educação}

Para compreender a limitação da legislação quando menciona os "profissionais da educação", vamos considerar neste artigo a definição de educação como "processo de transmissão e indução de cultura que se dá no convívio entre gerações numa determinada sociedade. Já educação escolar é o mesmo processo de educação quando se dá no âmbito de uma instituição específica, de forma intencional e sistemática." (MONLEVADE, 2007).

As condições para prover educação em uma instituição específica (a escola), de forma intencional e sistemática, exigem condições pessoais específicas, que se traduzem em necessidades profissionais.

Ainda segundo o professor João Monlevade, o conceito de "profissional" exige, de forma direta, três coisas para que alguém seja reconhecido como profissional: a) sua especialização e competência num determinado saber ou fazer; $b$ ) o fato de esta pessoa sobreviver deste trabalho, e c) o fato de sua especialidade ser identificada e reconhecida socialmente. (MONLEVADE, 2007). 
Continua o professor Monlevade, afirmando que, mais recentemente, as sociedades organizaram a profissionalização em vários rituais como: a) habilitação escolar através de um curso de nível médio ou superior; que confere diploma; b) registro profissional em algum órgão corporativo ou estatal; c) carreira profissional, com ingresso por concurso ou outra modalidade seletiva, e d) sindicalização.

Dadas estas condições, temos um roteiro preciso e específico para a profissionalização dos educadores no Brasil. A CNTE entende que o profissionalismo na educação no Brasil leva em conta três condições básicas: carreira, formação e salário (VIEIRA, 2007). Se faltar um destes pontos, o tripé do profissionalismo da educação estará comprometido.

\section{Os profissionais da educação na legislação}

Ocorre que nossa legislação apresenta grandes lacunas e limites, que terminam por comprometer as iniciativas que favoreceriam a execução das políticas para assegurar o profissionalismo na educação.

É que, desde os tempos do Brasil Império, a flexibilização e a descentralização sempre foram marcas maiores em nossas leis. Basta uma rápida leitura na Lei de 15 de outubro de 1827, de D. Pedro I, sobre educação e faremos as devidas constatações na matéria. (VIEIRA, 2007, p. 13).

Essa forma de tratamento da educação é uma das heranças do período da colonização, inaugurado no Brasil com 50 nos de negação da escola primária, seguido depois de um período de atuação dos jesuítas, o que se estenderá por aproximadamente 200 anos, condicionando, de forma direta, o desenvolvimento de políticas educacionais no Brasil. (FERREIRA, 2015).

A verdade é que nunca se logrou que o poder público central tivesse responsabilidade relevante na escolarização da maior parte da população, e a legislação sempre legitimou essa situação.

A própria condição de "liberdade" de cada ente criar seu sistema de ensino, abriu a possibilidade de consagração das desigualdades regionais agudas, que sempre abriram brechas para a atuação da iniciativa privada, a tal ponto que a Constituição Federal de 1988 assegurou essa condição, sendo que quase três décadas após sua promulgação, ainda não logramos sua regulamentação.

As frágeis legislações sobre educação no Brasil atuam para negar o direito à educação pública, gratuita e de qualidade socialmente referenciada à maioria da população. Uma de suas características é a desarticulação curricular ou a sua verticalidade. Em que pese toda uma luta do movimento social, que tenta evitar o determinismo curricular, via de regra, os governos atuam para a centralização das ações pedagógicas e a 
descentralização financeira para os entes, o que possibilita uma forte ação concorrencial entre as esferas de governos subnacionais no desenvolvimento das políticas educacionais.

\section{Um empecilho à profissionalização}

Nossa história enquanto nação revela uma característica que desvela o projeto educacional pensado pelas elites para o Brasil. Vivemos inicialmente 50 anos sem uma escola primária. Na sequência, após 1550, os jesuítas foram os protagonistas de uma educação religiosa, seletiva e de gestão não-pública. O curto período do Império vai marcar o início de um projeto de descentralização da educação, sem que os entes tenham como preocupação a garantia de direitos. Também assim aconteceu com o advento da República e somente no século 20, com muita pressão da sociedade e das transformações econômicas e sociais é que a escola pública se volta para o atendimento das massas na sociedade brasileira. (MONLEVADE, 2000).

Se atender as massas através da escola pública não foi prioridade governamental nos quatro primeiros séculos na história do País, tampouco o foi a preocupação com a formação profissional, carreira e salário. As muitas dificuldades que vivenciamos hoje como a falta de professores em algumas áreas, ou o excesso de professores formados em outras, vem da falta de gestão pública e de planejamento estratégico da política de formação profissional para a educação.

O Estado brasileiro sempre teve uma atuação de "bombeiro", no sentido de "apagar o fogo" quanto à necessidade de profissionais. Assim, programas de aligeiramento da formação de professores foram artifícios lançados para oferecer, já nos anos 70 de século passado, quase sempre, mão de obra "qualificada" para atender uma demanda para a qual o Estado não havia-se preparado.

Na lacuna da Gestão Pública da Educação, a iniciativa privada sempre se favoreceu como opção para atendimento das necessidades locais. Sem legislação que a regulamente, sem controle do Estado, o resultado dessas políticas foram desastrosas do ponto de vista de promover anomalias na formação profissional, que se volta contra o próprio Estado, com exigências de mais investimentos para corrigir as distorções. É o caso hoje da chamada "segunda licenciatura" para os professores. (BRASIL, 2009b; 2016).

Há que se levar em conta que a Gestão Pública da Educação no Brasil, limitada pelo projeto hegemônico de dominação, que sempre manteve o País na condição de colônia dos países mais desenvolvidos, jamais conseguiu promover o desenvolvimento da Educação de forma global. Os gargalos sempre estiveram presentes, seja na educação básica ou superior.

Assim, a criação de leis nem sempre corresponderam com a real opção que se deve ter pela educação pública e a correspondente gestão pública. Se temos muitas leis em 
educação, há uma certa distância entre o que a legislação prevê de fato e as políticas que se desenvolvem para a maioria da população.

No caso da educação básica, como exemplo, a condição profissional dos funcionários de escola, via de regra, sempre foi ausente das políticas desenvolvidas. Pouco se pensou para a formação desse profissional no Brasil. No século 20, foram poucas as iniciativas, e elas se deram mais no nível local, sem qualquer iniciativa do poder central, que, seguindo a lógica da ausência do Estado ou do Estado Mínimo no final do século XX, sempre delegou as iniciativas para os entes locais. No caso dos funcionários de escola, o resultado era previsível: pouca ou nenhuma ação para a valorização deste profissional.

\section{Referências legislacionais na CF de 1988}

Em que pese a Constituição Federal de 1988 ser considerada uma Constituição Cidadã, por assegurar avanços importantes em Direitos Sociais, em termos de reconhecimento e promoção do profissionalismo dos educadores no Brasil, ainda revela a fragilidade histórica de nossas legislações.

O texto original da Constituição Federal de 1988, em seu artigo 206, determinou:

Art. 206. O ensino será ministrado com base nos seguintes princípios: [...] V valorização dos profissionais do ensino, garantido, na forma da lei, planos de carreira para o magistério público, com piso salarial profissional e ingresso exclusivamente por concurso público de provas e títulos, assegurado regime jurídico único para todas as instituições mantidas pela União; [...]. (BRASIL, 2009a).

Ele revela uma característica central na Constituição, que é marca histórica nas demais legislações, referência direta aos "profissionais do ensino", o que supõe as funções docentes e correlatas.

No mesmo sentido vieram as leis subsequentes: a Lei de Diretrizes e Bases da Educação Nacional (BRASIL, 1996b) e a política de valorização salarial do magistério, estabelecida na Emenda Constitucional nº 14, de 1996 que instituiu o Fundef.

\section{Referências legislacionais nos anos 2000}

As marcas de uma legislação frágil e de ações descentralizadas ou carentes de regulamentação apenas cederam espaço para legislações mais concretas na formulação de políticas de valorização dos profissionais da educação básica, com a eleição do Governo Democrático e Popular de Luís Inácio Lula da Silva, em seu primeiro mandato (2003-2006). 
A pressão da sociedade civil organizada, do movimento sindical na educação básica, liderada pela CNTE, exigiu a superação da legislação fragmentária do tratamento da educação pública e valorização dos profissionais da educação.

Através de eleições de representantes sindicais para o Congresso Brasileiro, advindos do movimento sindical na educação, importantes avanços foram conquistados para as mudanças na legislação. Um novo patamar de fundamentos legais foi estabelecido,

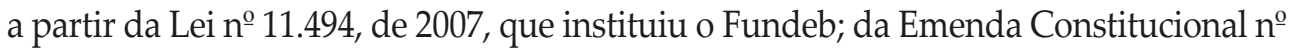
59, de 2009, que instituiu novas exigências para o Direito à Educação, e da Lei n⿳ㅜㅜ 12.014, de 2009, que alterou o artigo 61 da LDB, estabelecendo em definitivo as bases do reconhecimento do profissionalismo na educação brasileira, entre tantas leis importantes para a educação.

\section{Avanços e limites no Governo Lula}

É preciso considerar como enormes os avanços nas leis conquistadas na educação, principalmente no segundo governo do presidente Luis Inácio Lula da Silva. Mas chama a atenção que a adoção de políticas nos pontos considerados base para o profissionalismo na educação brasileira não passa de ações governamentais, instituídas em programas e políticas, ausentes de uma condição de imposição como política pública de Estado.

Destaque deve ser dado à Política Nacional de Formação, implementada pelo Decreto Presidencial (Decreto nº 6.755, de 2009 já revogado pelo Decreto nํㅗ․752, de 2016). Em que pese tratar apenas da Formação Profissional do Magistério, o destaque a ser feito é que a condição de uma política dessa magnitude ser instituída por decreto presidencial revela as disputas que envolvem uma educação que deveria ser de caráter estatal e as dificuldades de torná-la uma política de Estado na educação.

Com relação ao salário, a Lei no de 11.738, de 2008, que instituiu o Piso Salarial Nacional do Magistério, central para a valorização dos professores no País, revela o limite histórico de pensar o desenvolvimento profissional na educação, deixando de abarcar os demais profissionais que atuam no espaço escolar.

Neste sentido a luta histórica do movimento sindical na educação para assegurar na Constituição as Diretrizes de Carreira dos Profissionais da Educação encontra resistência nos governos municipais e estaduais, que não somam esforços para a valorização profissional, nem mesmo para assegurar a aplicação da Lei no 11.738 , de 2008 .

Destaque deve ser dado também à Política Nacional de Profissionalização dos Funcionários de Escola. Com ações de fortalecimento dos sistemas, o Programa teve seu maior pico de investimento no primeiro Governo Lula e perde força de política nos governos sequentes. 
Fato é que as iniciativas para assegurar valorização profissional do segmento de funcionários da educação sempre exigiram muita articulação e luta local dos trabalhadores e das trabalhadoras da educação, através da fundamental luta sindical da CNTE e seus sindicatos filiados, uma vez que em termos de legislação, este segmento não tem sido contado para efeito das políticas vinculantes de investimentos em valorização profissional.

\section{Das ações ideais à realidade da Lei}

Depois de décadas de intensos debates no Congresso Nacional, logramos, no início deste século, inaugurar a era dos planos decenais no planejamento das políticas educacionais no Brasil.

O Plano Nacional de Educação, a Lei nº 10.171, de 2001, sancionado pelo Governo Fernando Henrique Cardoso da Aliança PSDB-DEM, inviabilizou a execução do PNE (2001 - 2010), ao vetar todos os artigos que tratavam do financiamento das ações, inclusive o que visava ampliar os investimentos em educação até o final da década, em pelo menos 7\% do PIB. O plano se tornou uma mera carta de intenções. Não fosse a reorientação de governo à frente da nação, os resultados educacionais poderiam ter sido piores naquela década.

O Plano repetia as mesmas práticas ambíguas das legislações anteriores ao tocar a questões da valorização profissional, revertendo as ações apenas para o magistério.

Foram necessárias pressões da sociedade brasileira, através do movimento social e sindical para que o Governo Lula convocasse a primeira Conferência Nacional de Educação em 2010 (Conae/2010).

A Conferência tocou na maior necessidade do País: a instituição do Sistema Nacional de Educação, capaz de regulamentar as políticas e assegurar a educação como dever do Estado e direito da população.

Quatro anos depois, nova conferência se realizou, agora com o desafio de apontar as diretrizes para a construção do Plano Nacional de Educação, dentro de patamares de elevação do PIB para investimento em educação, reivindicados pela sociedade brasileira.

O resultado da Conae/2014 foi de grande valia para assegurar linhas de ação para a valorização, não mais dos profissionais do magistério, mas dos profissionais da educação.

Assim, o Plano Nacional da Educação, contido na Lei no 13.005, de 2014, dedica importantes metas para a valorização dos profissionais da educação no Brasil (CNTE).

Em que pese as contradições do próprio Plano, como não prever que recursos públicos apenas devem ser aplicados na educação pública, as ações de valorização dos profissionais da educação estarão a nos desafiar nos próximos dez anos. Num cenário crescente de disputa de recursos públicos da educação pela iniciativa privada, as incertezas sobre a real adoção de políticas de Estado na educação irão se aprofundar. 
Se antes não havia a adoção do conceito de "profissionais da educação" pela dubiedade dos termos na legislação, agora, a incerteza se mantém presente pelo simples fato de que os recursos previstos poderão ser apropriados pelas empresas privadas, sejam elas nacionais ou multinacionais.

\section{Governo do Golpe e novos desafios para a educação}

A realidade política brasileira no pós-eleição da presidenta Dilma Rousseff para o segundo mandato (2015-2018) à frente da Presidência, redefine o cenário de prioridade na educação.

Entre as medidas do governo golpista de Michel Temer - Henrique Meirelles, entre outras que estão em curso na plataforma "Ponte para o Futuro" do PMDB (PMDB, 2015) e no Congresso Nacional, estão:

» Proposta de acabar com a vinculação das receitas obrigatórias da União, Estados e Municípios para Educação e Saúde ("Ponte para o futuro", p. 09);

» Emenda Constitucional que possibilita às universidades públicas cobrarem pelos cursos de extensão e de pós-graduação (proposta por Alex Canziani, do PTB);

» Abertura do capital da Petrobras (privatização) e revisão do marco regulatório da partilha do pré-sal (encabeçada por José Serra-PSDB), que significa o fim dos royalties do fundo social do pré-sal para a educação e saúde;

» Projeto de lei “Escola sem partido" (apresentado pelo deputado Izalci, do PSDB) que propõe a "neutralidade" do professor com o fim das discussões políticas nas escolas e a proibição de manifestações estudantis em ambiente escolar;

» Proibição da discussão sobre gênero e diversidade sexual dentro dos princípios de Planos Nacional, Estaduais e Municipais de Educação (encabeçado pela bancada evangélica).

Enfim, são muitos os desafios para se garantir a nova concepção na legislação sobre os profissionais da educação. O maior risco é o retrocesso, o retorno à legislação retrógada no âmbito das regulamentações.

Fato é que, com o atual Congresso, teremos poucas chances de ver "vingar" as conquistas obtidas com muita luta. Agora, mais que antes, valerá o ditado que afirma: "é a luta que faz a lei".

Então, vamos à luta!

Sempre! 


\section{Referências}

BRASIL. Constituição (1988). Constituição da República Federativa do Brasil. Brasília: Senado Federal, 1988a.

Constituição (1988). Emenda Constitucional no 14, de 1996. Brasília, 1996a. Disponível em: <http://www.planalto.gov.br/ccivil_03/constituicao/emendas/emc/emc14.htm>. Acesso em: 03 jul. 2016.

. Constituição (1988). Emenda Constitucional no 59, de 2009. Brasília, 2009a. Disponível em: <http://www.planalto.gov.br/ccivil_03/Constituicao/Emendas/Emc/emc59.htm>. Acesso em: 03 jul. 2016.

Constituição Brasileira: texto original de 1988. Brasília, 1988b. Disponível em: <http:// crfb20anos.net84.net/1_14_Texto-Original-1988-.html>. Acesso em: 03 jul. 2016.

Câmara dos Deputados. Projeto de Lei $\mathbf{n}^{\mathrm{o}}$ 2.826, de $\mathbf{1}^{\mathrm{o}}$ de dezembro de 2011. Estabelece os princípios e as diretrizes dos planos de carreira para os profissionais da educação básica pública, em conformidade com o art. 206, V da Constituição Federal. Brasília, DF, Câmara dos Deputados, Atividade Legislativa, Projetos de Lei e Outras Proposições, 2011.

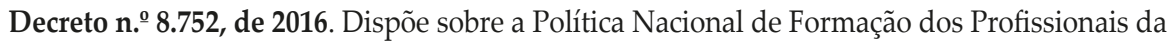
Educação Básica. Disponível em: <http://www.planalto.gov.br/ccivil_03/_Ato2015-2018/2016/Decreto/ D8752.htm>. Acesso em: 03 jul. 2016.

Decreto n.ำ 6.755, de 2009. Institui a Política de Formação Profissional do Magistério. 2009. Brasília, 2009b. Disponível em: <http://www.planalto.gov.br/ccivil_03/_ato2007-2010/2009/decreto/ d6755.htm>. Acesso em: 03 jul. 2016.

Lei $\mathbf{n}^{\mathbf{0}} \mathbf{1 0 . 1 7 1}$, de 5 de janeiro de 2001. Estima a Receita e fixa a Despesa da União para o exercício financeiro de 2001. Disponível em: <http://www.planalto.gov.br/ccivil_03/leis/LEIS_2001/ L10171.htm>. Acesso em: 03 jul. 2016.

Lei $\mathrm{n}^{-}$12.014, de 6 de agosto de 2009. Altera o art. 61 da Lei n⿳0 9.394, de 20 de dezembro de 1996, com a finalidade de discriminar as categorias de trabalhadores que se devem considerar profissionais da educação. Diário Oficial [da] República Federativa do Brasil, Brasília, DF, 7 ago. 2009c. Seção 1.

Lei n.0 9.394, de 20 de dezembro de 1996. Estabelece as diretrizes e bases da educação nacional. Diário Oficial [da] República Federativa do Brasil, Brasília, DF, 23 dez. 1996b. Seção 1.

Lei n. $\mathbf{0} 11.494$, de 20 de junho de 2007. Regulamenta o Fundo de manutenção e desenvolvimento da educação básica e de valorização dos profissionais da educação - FUNDEB... Disponível em: <http://www.planalto.gov.br/ccivil_03/_ato2007-2010/2007/lei/111494.htm>. Acesso em: 03 jul. 2016.

. Lei $\mathrm{n}^{\mathrm{o}} 11.738$, de 16 de julho de 2008. Regulamenta a alínea " $\mathrm{e}$ " do inciso III do caput do art. 60 do Ato das Disposições Constitucionais Transitórias, para instituir o piso salarial profissional nacional para os profissionais do magistério público da educação básica. Diário Oficial [da] República Federativa do Brasil, Brasília, DF, 17 jul. 2008. Seção 1.

Lei n. ${ }^{\mathbf{0}}$ 13.005, de 25 de junho de 2014. Aprova o Plano Nacional de Educação - PNE e dá outras providências. Disponível em: <http://www.planalto.gov.br/ccivil_03/_ato2011-2014/2014/lei/113005. htm>. Acesso em: 03 jul. 2016. 
. Ministério da Educação. Por uma política de valorização dos trabalhadores em educação: em cena, os funcionários de escola. Brasília, 2004. Disponível em: <http://portal.mec.gov.br/seb/arquivos/ pdf/em_cena.pdf>. Acesso em: 03 jul. 2016.

DOURADO, Luiz Fernandez. Uma política de Estado para a carreira na educação básica. Cadernos de Educação, Brasília, v. 21, 2 ed., out. 2009.

EDUCAÇÃO básica obrigatória. Retratos da Escola, Brasília, v. 4, n. 7, jul./dez. 2010.

EDUCAÇÃO em risco. Jornal Mural, CNTE, Brasília, maio 2016. Disponível em: <http://www.cnte.org. br/images/stories/2016/jornal_mural_maio_2016_prova1.pdf>. Acesso em: 03 jul. 2016.

FERREIRA, Gilmar Soares. Projeto Pensar a Educação Pensar o Brasil 1822-2022. Coleção Pensar a Educação Pensar o Brasil. In: SANTOS, Hercules Pimenta dos; PACHECO, Raquel Menezes (Org.). Que Educação, Para Que País? Belo Horizonte: Editora Mazza, 2015.

FREITAS, Helena Costa Lopes de; VIEIRA, Juçara Dutra; AGUIAR, Márcia Ângela da Silva Aguiar. Verbos intransitivos para uma política pública: formar, valorizar, profissionalizar. Retratos da Escola, Brasília, DF, v. 2, n. 2-3, p. 15-27, jan./dez. 2008. Entrevista. Disponível em: <http://www.cnte.org.br/ images/stories/2012/revista_retratosdaescola_02_03_2008_b_entrevista.pdf>. Acesso em: 18 jul. 2016.

GUARESCHI, Pedrinho. Sociologia crítica: alternativas de mudanças. 48. ed. Porto Alegre: EDIPUCRS, 2000. Cap. sobre Ideologia.

MONLEVADE, João A. Cabral de. Valorização salarial dos professores: o papel do piso salarial profissional nacional como instrumento de valorização dos professores da educação básica pública. 2000. Tese (Doutorado) - Universidade de Estadual de Campinas, Campinas, 2000.

. História do movimento sindical da educação no Brasil. Brasília: CNTE, 2007. p. 8-10. (Cadernos do Programa de Formação Sindical da CNTE, Fascículo V).

PMDB (Brasil). Uma ponte para o futuro. Brasília, 29 out. 2015. Documento. Disponível em: http:// www.search.ask.com/web?l=dis\&q=documento+uma+ponte+para+o+futuro\&o=APN10641\&apn_dtid= ${ }^{\wedge} \mathrm{IME002} \wedge$ YY^BR\&shad=s_0042\&apn_uid=0552750462744695\&gct=ds\&apn_ptnrs=^AG2\&d=2-1238\&la ng=pt\&atb=sysid\%3D2\%3Aappid\%3D1238\%3Auid\%3Db4e8f43cb4c9de2c\%3Auc2\%3D259\%3Atypekbn \%3Da14978\%3Asrc\%3Dffb\%3Ao\%3DAPN10641\%3Atg\%3D\&p2=^AG2^IME002^YY^BR

VIEIRA, Juçara Dutra. Piso salarial nacional dos educadores: dois séculos de atraso. Brasília: CNTE, 2007.

Piso salarial para os educadores brasileiros: quem toma partido? Campinas, SP. Autores Associados, 2013. 


\title{
The education professional in the Brazilian Constitution
}

\begin{abstract}
The article shows how the gaps in brazilian legislation together with the successive managers of the educational system, have continuously contributed to the reduction of actions and contingency resources, and have ended up blocking the path to an improved social quality in our education, which has started mainly with a reduction in investment in people and in their professionalization.

Keywords: Educational legislation. Professional development. Management education. Policies for education.
\end{abstract}

\section{Le professionnel de l'éducation dans la Constitution Brésilienne}

RÉSUMÉ: L'article montre comment les lacunes de la législation brésilienne et les gestions éducatives successives promeuvent en permanence la rupture des actions et la pré-destination des ressources,et finissent par empêcher le cheminement vers la qualité sociale de notre éducation, qui commence, principalement, par un investiment en personnel et par la professionalisation de ce dernier.

Mots-clés: Législation éducative. Valorisation professionnelle. Gestion de l'éducation. Polítiques pour l'éducation.

\section{El profesional de la educación en la Constitución Brasileña}

RESUMEN: El artículo muestra de qué manera las lagunas en la legislación brasileña y las sucesivas gestiones educativas promueven de forma continua la ruptura de acciones y la contingentación de recursos, y terminan bloqueando el camino hacia la calidad social de nuestra educación, que comienza sobre todo con la inversión en personal y en su profesionalización.

Palabras clave: Legislación educativa. Valoración profesional. Gestión de la educación. Políticas para la educación. 